\title{
Shaking table model test and engineering practice of a new gypsum-adobe walls dwell- ing in Xinjiang autonomous region, China*
}

\author{
ZHOU Tie-gang" (周铁钢) HU Xin (胡 昕) YU Chang-xia (余长霞) \\ School of Civil Engineering, Xi' an University of Architecture and Technology, Xi' an 710055, China
}

\begin{abstract}
The paper introduces a new type of green building which suits for the construction of rural dwellings in Xinjiang, China. Results of the shaking table test on building model show that the single-layer gypsum-adobe structure has better seismic performance. And it also analyzes the construction features and engineering practice, which means that it is significant to extend this type of building to the drier regions in China.
\end{abstract}

Key words: gypsum-adobe walls; seismic performance; engineering practice

CLC number: P315.9 Document code: A

\section{Introduction}

As the southern Xinjiang is one of the most intense earthquake areas in the inland, where the natural conditions are formidable and the proportion of poor people is very large, recently, the anti-earthquake construction of rural dwellings has been vigorously promoted and obtained well achievement. At present, there have been some common anti-seismic forms, such as wood-brick structure, wooden-splint adobe structure, stone-wood structure, brick-masonry structure, wooden-frame adobe structure, wicker-adobe structure and so on, which are made use of local materials, so they cost much lower. In the Tekesi earthquake of M5.7 in Xinjiang, China in 2006, all of those structures according to the local seismic fortification criterion have not collapsed in seismic intensity zone 9 , while there were only minute cracks in walls in seismic intensity zone 8 .

Cast-in-place gypsum-adobe structure is also a new form, which suits for the constructions of poor rural dwellings in southern Xinjiang, where teems with gypsum. Considering this superiority, we regard gypsum and adobe as primary materials, laying cotton straws on every adobe layer, and then casting gypsum slurry in the interstices among adobes to compose compound walls, the two materials in which interact together to display the respective performance fully.

Combining with the shaking table model test of gypsum-adobe walls dwelling ${ }^{\circledR}$, the paper primarily analyzes its seismic performance and briefly introduces its engineering practice in southern Xinjiang, China.

\footnotetext{
* Received 2007-12-26; accepted in revised form 2008-04-10.

Foundation item: Science and Technology Key Projects of the Construction Department of Xinjiang Uygur Autonomous Region.

* Author for correspondence: Zhoutiegangen@126.com

${ }^{(1)}$ ZHOU Tie-gang, KANG Ling-guo, LI Xiao-wen. 2007. Report of shaking table test for seismic comfortable housing project in Xinjiang autonomous region $[R]$. 1-35.
} 


\section{Designing and constructing the model}

\subsection{Test objective}

As a new cast-in-place structure, combined with two low strength materials (adobe and gypsum), the compound wall structure has not been seen in China and abroad, previously. Thus, firstly, we will seek for the feasibility of its construction technology by making models.

Secondly, by shaking table test, we will test the model's dynamic characteristics and earthquake responses under different working stages; observe and record failure modes and failure characteristics under all intensities; evaluate seismic performances of the prototype building and then propose some improvement suggestions.

\subsection{Building prototype}

The bay dimension of the prototype with single-floor and two-bay, are $3.3 \mathrm{~m} \times 5.1 \mathrm{~m}$ and 3.6 $\mathrm{m} \times 5.1 \mathrm{~m}$, the clear height of which is $2.5 \mathrm{~m}$. The adobe size is $(330 \times 160 \times 70) \mathrm{mm}$; the gypsum thickness covering the inside and the outside of walls is $50 \mathrm{~mm}$; and that of external wall is 430 $\mathrm{mm}$, and that of the internal wall is $260 \mathrm{~mm}$. The wooden truss roof is adopted, above which is vertical timber and purlin plank sheathing, and thermal insulation material (clay with straw) on the roof is $150 \mathrm{~mm}$. The external wall configuration is showed in Figure 1.
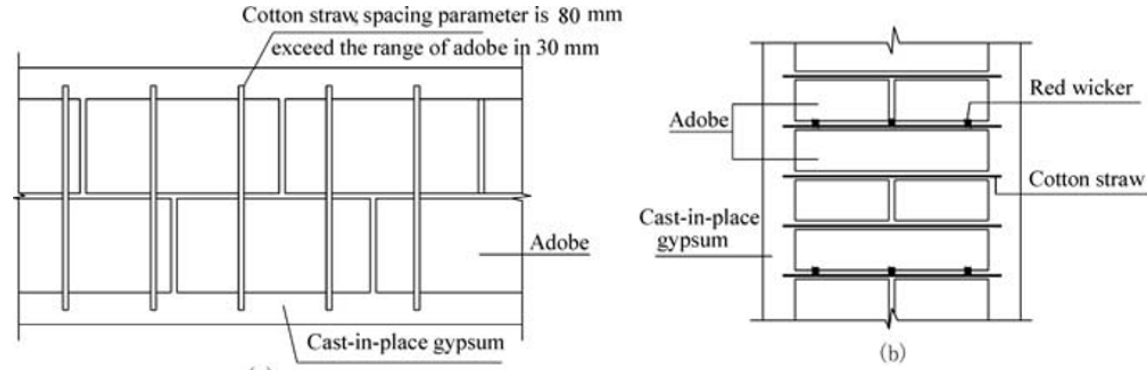

(a)

Figure 1 Wall configuration

(a) Plan of external wall; (b) Section of external wall

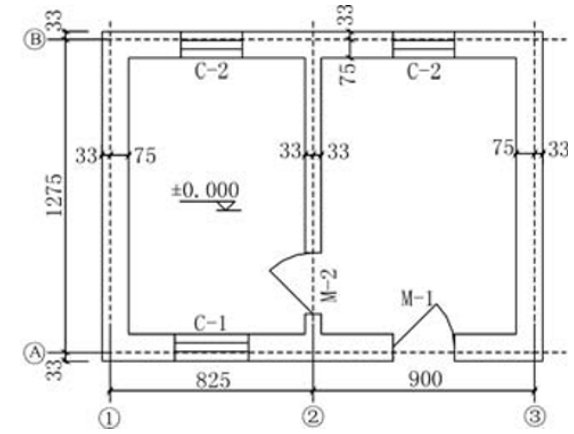

Figure 2 Model plan

\subsection{Designing the model}

According to the shaking table size and vertical loads, the model scaling factor is $1: 4$, as shown in Figure 2.

The model materials, such as gypsum with low strength procured in small local kilns (compressive strength is about $2.5 \mathrm{MPa}$ ), is completely simulated to the actual situation in southern Xinjiang. Adobe model size is $(82 \times 39 \times 30) \mathrm{mm}$; cotton straw diameter is between $4 \sim 6 \mathrm{~mm}$, and the wood purlines are local poplars. Because of neglected gravity model (YAO and LIU, 1996; WU et al, 1997), the dynamic similarity relation of which is showed in Table 1.

\subsection{Making the model}

From December 15, 2006, we began to make our model in the Structure and Seismic Testing Laboratory of Xi'an University of Architecture and Technology (Ministry of Education Key 
Testing Laboratory). When the base concrete strength was up to $70 \%$ designed strength, we framed templates at first, placed adobes and cotton straws according to the design, laid continuous wickers (connecting effect) every two adobe layers and then poured slurry for three times, the proportion of gypsum and water in which is 1:1 (volume ratio). After two hours, we

Table 1 Similarity relations

\begin{tabular}{cclc}
\hline Physical quantity & Dimension & Similarity relation & Ratio \\
\hline$L$ & $L$ & $c_{l}=l_{m} / l_{p}$ & $1 / 4$ \\
$M$ & $F L^{-1} T^{-2}$ & $c_{m}=c_{\rho} c_{l}^{3}$ & $1 / 64$ \\
$T$ & $T$ & $c_{f}=c_{l}\left(c_{\rho} / c_{E}\right)^{1 / 2}$ & $1 / 4$ \\
$f$ & $T^{-1}$ & $c_{f}=c_{l}^{-1}\left(c_{E} / c_{\rho}\right)^{1 / 2}$ & 4 \\
$v$ & $L T^{-1}$ & $c_{v}=\left(c_{E} / c_{\rho}\right)^{1 / 2}$ & 1 \\
$a$ & $L T^{-2}$ & $c_{a}=c_{E} / c_{l} c_{\rho}$ & 4 \\
\hline Note: $L$ denotes length, $M$ quality, $T$ cycle, $f$ frequency, $v$ velocity and
\end{tabular}
demolished these templates, owing to the gypsum's rapid solidification, then disposed wood-beams and purlines, and eventually finished the roof. The crux of the progress is that the mix proportion of gypsum and water must be controlled strictly, and the proper temperature of water is $30 \sim 35$ degree.

After all the templates were removed, the dimension of the model was $1.8 \mathrm{~m} \times 1.35 \mathrm{~m} \times 0.72$ $\mathrm{m}$, the thickness of external walls was $108 \mathrm{~mm}$ and that of internal walls was $66 \mathrm{~mm}$. The model construction is showed in Figure 3.
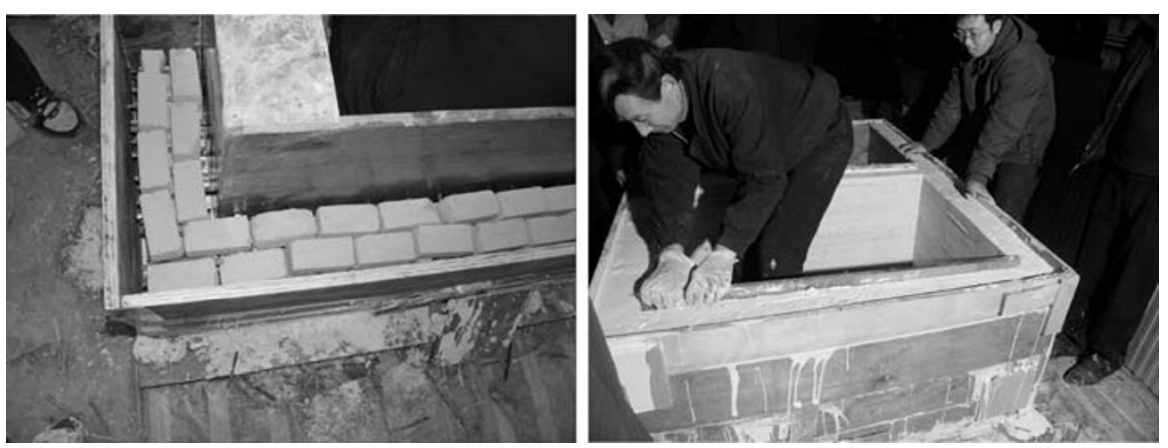

Figure 3 Construction of main structure

\subsection{Arrangement of instruments}

After having been dried, the model was hoisted on to the shaking table to fix the position of acceleration sensors, shown in Figure 4.

\section{Procedure of test}

\subsection{Measurement on dynamic characteristics}

Firstly, knocking the model is for the research on dynamic characteristics of the building to get the natural frequency $3.7 \mathrm{~Hz}$. Then, we know that the natural frequency $3.7 \mathrm{~Hz}, 3.5 \mathrm{~Hz}$ and $3.4 \mathrm{~Hz}$ are corresponding to intensity 7,8 and 8.5 , respectively.

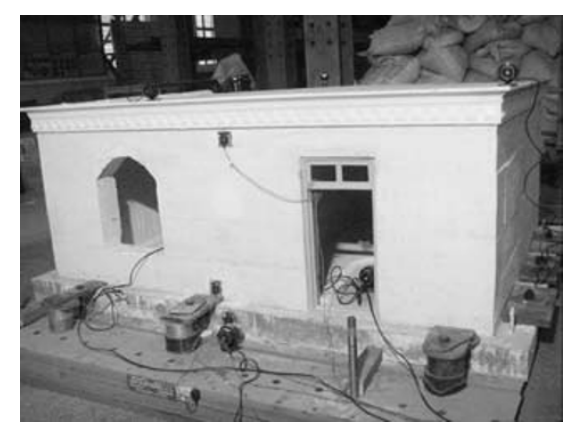

Figure 4 Model sensor arrangement

\subsection{Process of shaking table test}

As the ELcentro-wave is adopted, all the phenomenon of the model during the test is described as follows, as shown in Figure 5. 


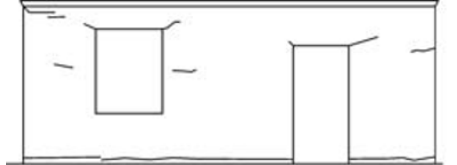

(a)

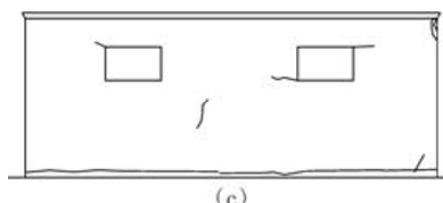

(c)

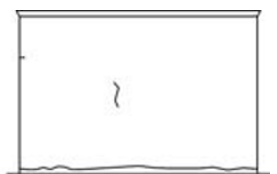

(b)

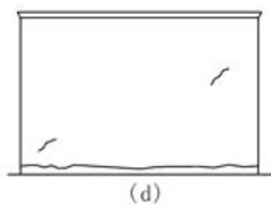

Figure 5 Cracks of the structure

(a) Front elevation; (b) North wall; (c) Rear elevation; (d) South wall

dow-hole was about $0.5 \mathrm{~mm}$ width and $5 \mathrm{~cm}$ length.

When the peak acceleration of shaking table was $0.449 \mathrm{~m} \cdot \mathrm{s}^{-2}$ (moderate intensity 7), there were inclined cracks, with width $0.5 \mathrm{~mm}$ and length $3 \mathrm{~cm}$ at the right upper corner near the front gate-hole and 45 degree inclined cracks, with width $0.3 \mathrm{~mm}$ and length $2 \mathrm{~cm}$ at the left upper corner near the back left window-hole.

When the peak acceleration of shaking table was $0.780 \mathrm{~m} \cdot \mathrm{s}^{-2}$ (moderate intensity 8 ), horizontal crack at the right upper corner near the back right win-

When the peak acceleration of shaking table was $1.245 \mathrm{~m} \cdot \mathrm{s}^{-2}$ (moderate intensity 8.5 ), there were a inclined crack with length $6 \mathrm{~cm}$ near internal wall as well as closing with the front gate-hole, and a inclined crack with length $3 \mathrm{~cm}$ at the right underside corner of the back wall. Those cracks near the front gate-hole and back left window-hole were cracking; while the joint area between southeast wall bottom and concrete base had been ripped.

When the peak acceleration of shaking table was $1.690 \mathrm{~m} \cdot \mathrm{s}^{-2}$ (equal to moderate intensity 9 and rare intensity 8), vertical cracks in the middle of the north wall was $0.5 \mathrm{~mm}$ width, $10 \mathrm{~cm}$ length; a new inclined crack in internal wall was $4 \mathrm{~cm}$ length; and there was micro-displacement between the wall bottom and the concrete foundation.

When the peak acceleration of shaking table was $2.400 \mathrm{~m} \cdot \mathrm{s}^{-2}$ (rare intensity 9), 3\# and 4\# displacement sensors fell off the roof with the intense vibration, and then the model were destroyed. It was characterized by the run-through of horizontal cracks at bottom of walls and large displacement between the structure and the concrete foundation.

\section{Analysis on test results}

\subsection{Dynamic characteristics}

According to the hammering test result, we can see that natural frequency decays with the increase of seismic wave peak, but not very fast, that means structural stiffness has degenerated. So, according to the similarity relation, the first frequency of prototype structure is $0.98 \mathrm{~Hz}$.

\subsection{Seismic response}

1) Acceleration response of the model

Figure 6 shows the time history plot of acceleration of the model under different working stages.

All the dynamic magnification factors $\beta$ are ratios of the maximal top-accelerations to the maximal base-accelerations, shown in Table 2.

2) Displacement response of the model

Table 2 Dynamic magnification factors $\beta$

\begin{tabular}{clll}
\hline Working stages & $\beta$ & Working stages & $\beta$ \\
\hline Moderate intensity 7 & 1.39 & Moderate intensity 9 & 1.17 \\
Moderate intensity 8 & 1.33 & Rare intensity 8 & \\
Moderate intensity 8.5 & 1.21 & Rare intensity 9 & 1.13 \\
\hline
\end{tabular}

There are some corresponding peak displacements depending on the displacement sensors under different seismic wave peaks. All the 
maximal relative top-displacements and displacement-angles under different working stages are showed in Table 3.
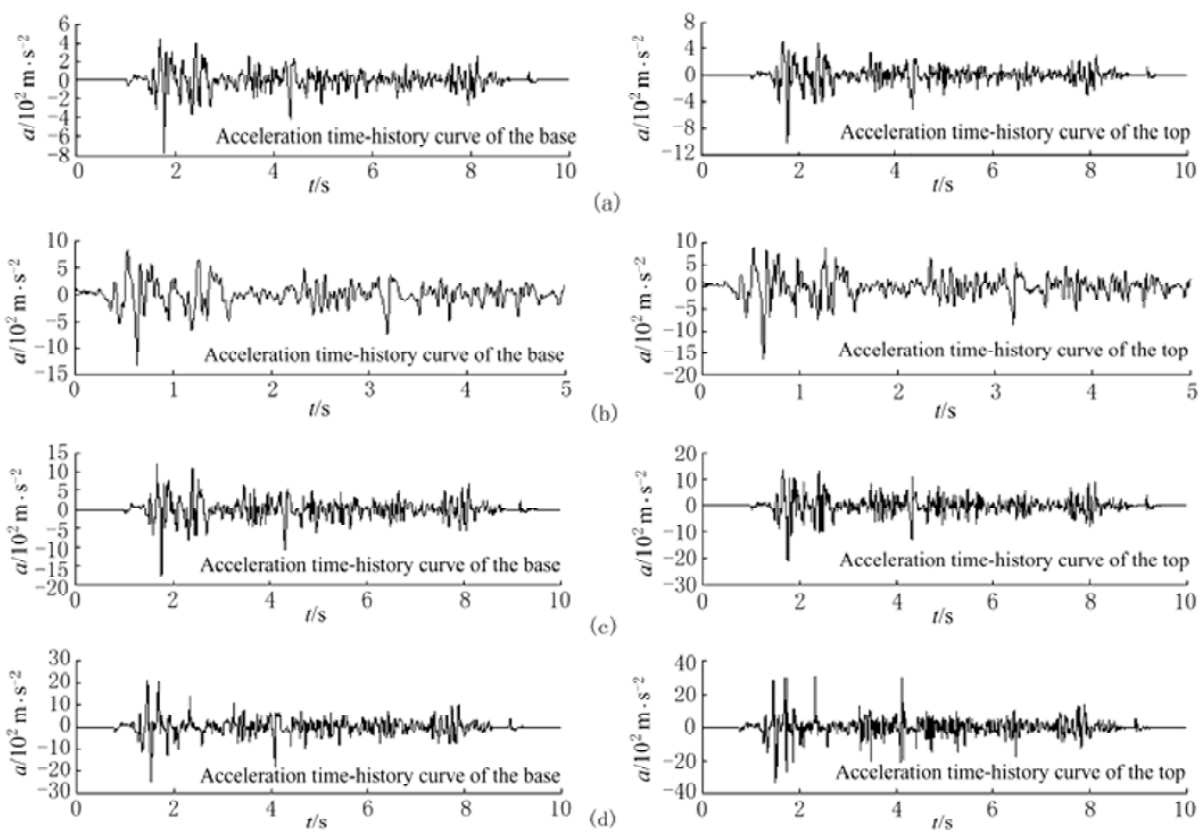

Figure 6 Acceleration time-history curves of the model

(a) Peak acceleration: $0.780 \mathrm{~m} \cdot \mathrm{s}^{-2}$; (b) Peak acceleration: $1.245 \mathrm{~m} \cdot \mathrm{s}^{-2}$; (c) Peak acceleration: $1.690 \mathrm{~m} \cdot \mathrm{s}^{-2}$;

(d) Peak acceleration: $2.400 \mathrm{~m} \cdot \mathrm{s}^{-2}$

Table 3 Relative top-displacements and displacement angles

\begin{tabular}{lcc}
\hline \multicolumn{1}{c}{ Working stages } & $\begin{array}{c}\text { Relative top- } \\
\text { displacements } / \mathrm{mm}\end{array}$ & Displacement angles \\
Moderate intensity 7 & 0.420 & $1 / 1714$ \\
Moderate intensity 8 & 1.014 & $1 / 710$ \\
Moderate intensity 8.5 & 2.198 & $1 / 328$ \\
Moderate intensity 9 & 2.722 & $1 / 265$ \\
rare intensity 8 & & \\
\hline
\end{tabular}

\subsection{Preliminary conclusions}

Preliminary conclusions from the test are showed as follows:

(1) It is obvious that the structure's natural frequency is lower and natural period relatively long according to the measurement results of dynamic characteristics.

(2) It can be seen from the shaking table that the structure's integrity is so good to resist earthquake, because there are few cracks in walls. When the peak acceleration of shaking table was $2.400 \mathrm{~m} \cdot \mathrm{s}^{-2}$ equaling to rare intensity 9 , there is large displacement between the model and the base, more cracks in walls, but the main structure does not collapse and keeps its integrity, basically.

\section{Project practice}

Our team had done the first Pilot Project in Tierimu Town, Jiashi County in southern Xinjiang, as shown in Figure 7, during March to August in 1997, after the test. Till now, there more than 1000 gypsum-adobe wall buildings have been constructed in the whole county. During the time, many groups of the administrations in Hetian, Korla, Aksu, Turpan in Xinjiang came there to investigate and study, so this structure has been extended gradually in these areas. 


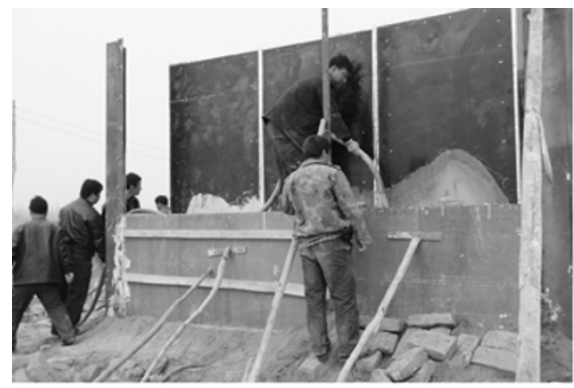

(a)

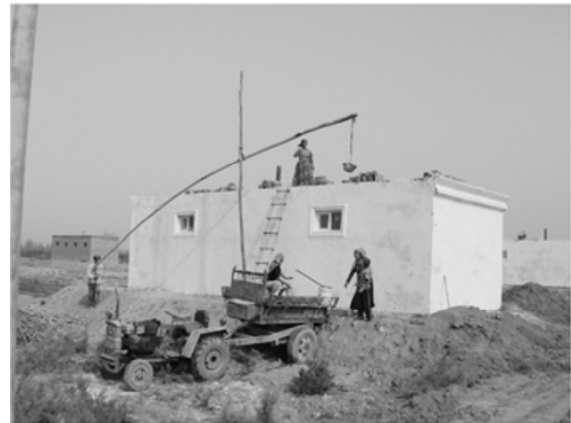

(c)

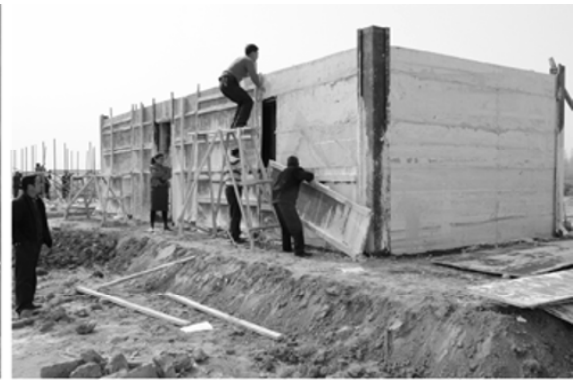

(b)

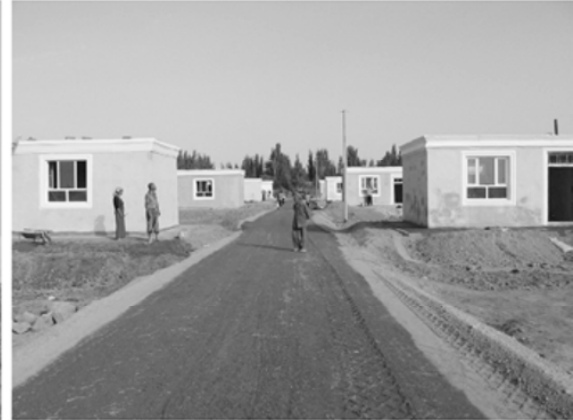

(d)

Figure 7 Pilot project construction

(a) Wall pouring; (b) Wall form removal; (c) Roof construction; (d) Village of pilot project

\section{Conclusions}

Above all, with the application of the local green ecological material, cast-in-place gypsum-adobe wall structure has convenient construction and well anti-seismic, and suits for the construction of rural dwellings in South Xinjiang and other arid regions in China. Of course, as a new structure, there are still many questions to be solved. At present, our group are doing the subsequent tests and tracking the houses having been built.

\section{References}

WU Shi-ying, DONG Shi-min, HUANG Hao-hua, et al. 1997. Regulation of seismic test method of Buildings (JGJ 101-96): the first edition [S]. Beijing: China Construction Industry Press: 24-27.

YAO Zhen-gang and LIU Zu-hua. 1996. Structure Experiment: the first edition [M]. Shanghai: Tongji University Press: 17-25. 